\title{
Oxidative Stress Is Responsible for Deficient Survival and Dendritogenesis in Purkinje Neurons from Ataxia- Telangiectasia Mutated Mutant Mice
}

\author{
Philip Chen, ${ }^{1}$ Cheng Peng, ${ }^{1}$ John Luff, ${ }^{1}$ Kevin Spring, ${ }^{1}$ Dianne Watters, ${ }^{2}$ Steven Bottle, ${ }^{3}$ Shigeki Furuya, ${ }^{4}$ and \\ Martin F. Lavin ${ }^{1,5}$ \\ ${ }^{1}$ The Queensland Institute of Medical Research, Royal Brisbane Hospital, Herston, Queensland 4029, Australia, ${ }^{2}$ School of Biomolecular and Biomedical \\ Sciences, Griffith University, Nathan Campus, Brisbane, Queensland 4111, Australia, ${ }^{3}$ School of Physical Sciences, Queensland University of Technology, \\ Brisbane 4001, Australia, ${ }^{4}$ ational Circuit Mechanisms Research Group, Brain Science Institute, RIKEN, Saitama, 351-0198, Japan, and ${ }^{5}$ Department of \\ Surgery, University of Queensland, Royal Brisbane Hospital, Herston, Queensland 4029, Australia
}

\begin{abstract}
Atm gene-disrupted mice recapitulate the majority of characteristics observed in patients with the genetic disorder ataxia-telangiectasia (A-T). However, although they exhibit defects in neuromotor function and a distinct neurological phenotype, they do not show the progressive neurodegeneration seen in human patients, but there is evidence that ataxia-telangiectasia mutated (Atm)-deficient animals have elevated levels of oxidized macromolecules and some neuropathology. We report here that in vitro survival of cerebellar Purkinje cells from both Atm "knock-out" and Atm "knock-in" mice was significantly reduced compared with their wild-type littermates. Although most of the Purkinje neurons from wild-type mice exhibited extensive dendritic elongation and branching under these conditions, most neurons from Atm-deficient mice had dramatically reduced dendritic branching. An antioxidant (isoindoline nitroxide) prevented Purkinje cell death in Atm-deficient mice and enhanced dendritogenesis to wild-type levels. Furthermore, administration of the antioxidant throughout pregnancy had a small enhancing effect on Purkinje neuron survival in Atm gene-disrupted animals and protected against oxidative stress in older animals. These data provide strong evidence for a defect in the cerebellum of Atm-deficient mice and suggest that oxidative stress contributes to this phenotype.
\end{abstract}

Key words: ataxia-telangiectasia; neurodegeneration; Purkinje neurons; oxidative stress; cell cultures; Atm mutant mice

\section{Introduction}

The most debilitating characteristic of the human genetic disorder ataxia-telangiectasia (A-T) is progressive neurodegeneration (Sedgwick and Boder, 1991). Ataxia is usually the earliest sign of the disorder, manifested as instability of gait associated with inappropriately narrow-base and lack of coordination of head and eyes (Boder, 1985). Prominent features developing at a later stage include dyssynergia and intention tremor, diminution of deep reflexes, and characteristic facies and postural attitudes caused by the cerebellar hypotonia and oculomotor signs, including apraxia of eye movement, fixation of gaze, nystagmus, and strabismus (Boder, 1985). Progressive atrophy of the cerebellar cortex is the most prominent but not the only neuropathological change in A-T (Boder, 1985). At autopsy it is evident that Purkinje cell numbers are reduced, ectopically located in the molecular layer, and a thinning of the granule cell layer also occurs (Sedgwick and Boder, 1991). Assessment of different neurological functions al-

\footnotetext{
Received July 9, 2003; revised Sept. 30, 2003; accepted 0ct. 3, 2003.

This work was supported by the Ataxia-Telangiectasia Children's Project (Florida) and the National Health and Medical Research Council of Australia. We thank Melanie Anderson and Louise Hughes for preparing this manuscript. Correspondence should be addressed to Prof. Martin Lavin, The Queensland Cancer Fund Research Unit, The Queensland Institute of Medical Research, P.0. Box Royal Brisbane Hospital, Herston, Brisbane 4029, Australia. E-mail:martinL@qimr.edu.au.

Copyright $\odot 2003$ Society for Neuroscience $\quad$ 0270-6474/03/2311453-08\$15.00/0
}

tered in A-T patients correlated well with age, and it appeared that severe and mild forms of the disease could be distinguished using these criteria (Crawford et al., 2000).

Mutations in the ataxia-telangiectasia mutated (ATM) gene give rise to A-T (Savitsky et al., 1995). This gene encodes a protein that is a member of the phosphoinositide 3-kinase family (Lavin and Shiloh, 1997), and activation of ATM by ionizing radiation leads to the phosphorylation of a multitude of substrates involved in recognition of double strand breaks in DNA and in cell cycle checkpoint activation (Shiloh and Kastan, 2001). Disruption of the Atm gene in mice produces a phenotype with many of the features of the human disease (Barlow et al., 1996; Elson et al., 1996; Xu et al., 1996; Herzog et al., 1998). These mice are extremely sensitive to radiation, are immunodeficient, infertile, and deficient in cell cycle control after irradiation, and most of the animals develop malignant thymic lymphomas. A knock-in Atm mouse harboring an in-frame deletion corresponding to the common human ATM mutant $7636 \mathrm{del} 9$ showed most of the A-T characteristics but had a variant tumor phenotype (Spring et al., 2001, 2002). Although neurologic abnormalities were described for Atm-deficient mice, none showed the gross neurodegenerative changes that characterize the human disease (Barlow et al., 1996). In one study, however, Kuljis et al. (1997), using electron microscopy, provided evidence of widespread neuronal degener- 
ation and glial activation in $\mathrm{Atm}^{-1-}$ mice, but Barlow et al. (2000) failed to observe morphological disorders in any area of the cerebellum in the same mice. Borgeshani et al. (2000) reported ectopic and abnormally differentiated Purkinje cells in Atm mutant mice but again no gross cerebellar degeneration. Although the mouse models do not reflect the neurodegenerative phenotype of A-T patients, evidence for a more subtle defect at the level of the cerebellum exists at least in some cases. It has been suggested that the neuronal defect may arise as a consequence of oxidative stress for which there is evidence in A-T cells and in the cerebellum of Atm-deficient mice (Barlow et al., 1996; Gatei et al., 2001; Stern et al., 2002).

To address the possible cerebellar abnormalities in Atmdeficient mice, we investigated Purkinje neuron survival and differentiation in vitro. We demonstrate reduced survival in cultured Purkinje cells from Atm knock-out and knock-in animals and a markedly reduced capacity for dendritic differentiation. Furthermore, correction of this phenotype with antioxidant suggests that oxidative stress contributes to a defective cerebellar phenotype in these mutants.

\section{Materials and Methods}

Atm-deficient mice. We used Atm knock-in mice (Atm- ${ }^{\Delta \mathrm{SRI} / \Delta \mathrm{SRI})}$ harboring an in-frame nine nucleotide deletion, 7666del9 (Spring et al., 2001). In addition, Atm ${ }^{-1-}$ mice were provided by P. Leder (Harvard Medical School, Boston, MA). In both cases their wild-type littermates were used as controls (129T2/SvEmsJ: C57 BL/6J).

Primary cultures of cerebellar Purkinje neurons. Culturing of cerebellar Purkinje cells was performed as described previously (Furuya et al., 1998). Briefly, newborn mice (0-1 d postnatal) were killed by decapitation, and individual cerebella were dissected and kept in cold HBSS. A section of tail was cut from each individual animal for genotyping. The cerebella were washed with HBSS once and digested with $0.1 \%$ trypsin at $35^{\circ} \mathrm{C}$ for $10-15 \mathrm{~min}$. The digested cerebella were rinsed twice with HBSS. Dissociation of the enzyme-treated cerebellum was done by gentle trituration in $0.05 \%$ DNase HBSS with an Eppendorf tip. After removal of the supernatant, dissociated cells were adjusted to a density of $5 \times 10^{6}$ cells per milliliter with DMEM/F12 supplemented with $10 \% \mathrm{FCS}$, and $2 \times 10^{5}$ cells were gently placed on each poly-L-ornithine-coated coverslip. Separate cultures were prepared for each animal. After 3-5 hr incubation under an atmosphere of $5 \% \mathrm{CO}_{2}, 25 \mu$ l of growth medium [DMEM/F12 supplemented with N-2 (Invitrogen, Gaithersburg, MD; catalog \#17502$048)$, BSA $(100 \mu \mathrm{g} / \mathrm{ml})$, cytosine arabinonucleoside $(2 \mu \mathrm{m})$, gentamicin $(10 \mu \mathrm{g} / \mathrm{ml})$, and tri-iodothyronine $(0.5 \mathrm{ng} / \mathrm{ml})]$ was added to each well.

Evaluation of Purkinje cells survival and differentiation. After 4 or $10 \mathrm{~d}$ in culture, cells were fixed with paraformaldehyde $(4 \% \mathrm{w} / \mathrm{v}$ in $0.1 \mathrm{M}$ sodium phosphate buffer, $\mathrm{pH}$ 7.0) for $30 \mathrm{~min}$ at room temperature. Purkinje cells were immunostained with anti-calbindin D-28K antibodies (C9848; Sigma, St. Louis, MO) and then with biotin-conjugated goat affinity-purified $\mathrm{F}\left(\mathrm{ab}^{\prime}\right) 2$ fragments to mouse IgG (55596; ICN Biochemicals, Costa Mesa, CA) and avidin-biotin mixture (Vectastain ABC Kit). Finally, cells were reacted with $\mathrm{DAB}$ reagent, and coverslips were mounted with DePex mounting medium (BDH). Purkinje cells were counted using a bright-field optics microscope. Neurons were counted in $5 \mathrm{~mm}^{2}$ fields for each animal, and statistical significance was established using a Student's $t$ test, one-tailed distribution, two-sample equal variance. To determine the degree of differentiation, neurons were categorized by numbers of primary dendrites and secondary branches within these categories. Wild-type and ATM-defined Purkinje cells were evaluated for average number of secondary branches within specific categories. Statistical significance between the two animal types was determined using the Student's $t$ test.

Antioxidant protection studies. Nitroxides are free-radical scavengers that offer protection against the lethal effects of ionizing radiation and also detoxify oxygen metabolites by redox cycling, which mimics the enzymatic action of superoxide dismutase. The fused aromatic moiety of the isoindoline skeleton provides resistance to the ring-opening reactions that are significant decomposition pathways for pyrrolidine and piperidine nitroxides and their oxoammonium salt redox partners (Bottle et al., 2000). We have recently addressed the solubility limitations of the currently available isoindoline class of nitroxides by the synthesis of 5-carboxy-1,1,3,3-tetramethylisoindolin-2-yloxyl (CTMIO), a compound that preserves the advantages of the isoindoline systems while possessing water solubility up to $\sim 2 \mathrm{~mm}$ (Bottle et al., 2000). CTMIO was synthesized as described previously using bromine functionalization of the isoindoline ring followed by $\mathrm{BuLi} / \mathrm{CO}_{2}$ and oxidation to give the carboxy-substituted nitroxide in good overall yield (Bottle et al., 2000). For primary cultures isolindoline nitroxide, CTMIO was used to protect Purkinje neurons against cell death caused by oxidative stress. Nitroxide was prepared as a stock solution in PBS (10 mM). Neuronal cultures were supplemented with $100 \mu \mathrm{M}$ CTMIO 3-6 hr after plating of the culture and at $48 \mathrm{hr}$ time intervals for the duration of the culturing. Cells were fixed as described above, and survival or dendritogenesis was determined. For in vivo protection, the effect of nitroxide on Purkinje cell survival was also determined using previous administration of $100 \mu \mathrm{M}$ in $200 \mu \mathrm{l}$ of PBS to pregnant females before mating and at intervals of $72 \mathrm{hr}$ thereafter throughout pregnancy. Once neuronal cultures were established from newborn mice, the same protocol as described above was used for the culturing period. In some experiments the effect of nitroxide was extended to investigate protection in animals up to 3 months of age. Here also pregnant animals were treated with nitroxide for the period of the pregnancy and to the weaning stage. After that the drinking water of litters was supplemented with $100 \mu \mathrm{M}$ nitroxide.

Assessment of effect of nitroxide on neurological status of Atm genedisrupted mice. In mice, disruption of the Atm gene gives rise to neuronal abnormalities (Borgeshani et al., 2000), and there is evidence that oxidative stress contributes to the phenotype (Barlow et al., 1999; Stern et al., 2002). We used two of the parameters reported in these studies, reduced catalase activity and evidence for the presence of 3-nitrotyrosine in the cerebella of Atm gene-disrupted mice, to assess protection by nitroxide. To determine catalase activity, cerebella were dissected from 2-monthold mice and homogenized in $400 \mu \mathrm{l}$ of $10 \mathrm{~mm}$ Tris- $\mathrm{HCl}, \mathrm{pH} 7$, containing digitonin $(0.1 \mathrm{mg} / \mathrm{ml})$ and $0.25 \mathrm{M}$ sucrose at $4^{\circ} \mathrm{C}$. Samples were kept on ice for $10 \mathrm{~min}$ before adding Triton X-100 at a final concentration of $0.1 \%$. The mixture was vortexed, and catalase activity was determined by a decrease in absorbance of $\mathrm{H}_{2} \mathrm{O}_{2}$ at $240 \mathrm{~mm}$ at $37^{\circ} \mathrm{C}$. Protein was determined by the Bradford method for determination of specific activities. Protein damage as a consequence of oxidative stress was determined using immunocytochemistry with antibodies against 3-nitrotyrosine (Cell Signaling Technology, Beverly, MA). Cerebella were fixed in paraformaldehyde, and $5 \mu \mathrm{m}$ sections were prepared. Sections were incubated with antibody (1:50 dilution) for $16 \mathrm{hr}$, and 3-nitrotyrosine was detected using anti-rabbit IgG, HRP-linked antibody.

\section{Results \\ Reduced survival of cerebellar neurons from $\mathrm{Atm}$ gene-disrupted mice}

Cerebella were dissected from newborn mice to prepare mixed neuronal cultures in serum and glial cell-free conditions as described by Furuya et al. (1998) for embryonic rats. Staining for Purkinje cells with calbindin failed to detect these cells in $10 \mathrm{~d}$ serum-free cultures from Atm gene-disrupted mice, whereas Purkinje cells were observed in cultures from wild-type littermates (data not shown). Accordingly, cultures were established in a richer medium (DMEM/F12) containing 1\% FCS to enhance the prospects of Purkinje cell survival in Atm mutants. Neuronal cultures were established for both knock-out $\left(\mathrm{Atm}^{-{ }^{-}}\right)$and knock-in $\left(\right.$ Atm- $\left.{ }^{\Delta \mathrm{SRI} / \Delta \mathrm{SRI}}\right)$ mice. Atm ${ }^{-1-}$ mice do not express any Atm protein because the truncated forms are highly unstable (Barlow et al., 1996; Elson et al., 1996), whereas Atm- $\Delta$ SRI/ $\Delta$ SRI mice express near full-length Atm mutant (2556del3) protein (Spring et al., 2001, 2002). In Atm- $\Delta$ SRI litters, the survival of homozygous mutant Purkinje cells was $<60 \%$ of that for wildtype littermates after $4 \mathrm{~d}$ in culture $(p<0.008)$ and $\sim 40 \%$ after 
Table 1. Purkinje neuron survival in vitro

\begin{tabular}{llrr}
\hline Litter & Animal numbers & \multicolumn{1}{c}{4 DIV $^{a}$} & \multicolumn{1}{c}{10 DIV } \\
\hline Atm- $\Delta$ SRI & & & \\
$\quad$ colony & & & \\
Atm $^{+/+b}$ & 15 & $219^{c} \pm 34^{d}$ & $154 \pm 25$ \\
Atm $^{\Delta S R / \Delta S R I}$ & 15 & $126 \pm 22$ & $65 \pm 10$ \\
Atm $^{-/-}$-deficient colony & & & \\
Atm $^{+/+}$ & 5 & $263 \pm 77$ & $185 \pm 40$ \\
Atm $^{-/-}$ & 5 & $99 \pm 35$ & $53 \pm 10$ \\
\hline
\end{tabular}

${ }^{a}$ DIV, Days in culture.

${ }^{b}$ Wild-type siblings from Atm- $\Delta$ SRI litters.

Numbers represent Purkinje neurons in $5 \mathrm{~mm}^{2}$ field.

${ }^{d}$ SEM.

$10 \mathrm{~d}(p<0.02)$ (Table 1). The corresponding survival levels for Atm $^{-1-}$ Purkinje cells were $40 \%(p<0.05)$ and 30\% $(p<0.02)$ of their wild-type littermates (Table 1$)$. When medium conditioned with cerebellar astroglial cells prepared from normal wildtype mice as described by Furuya et al. (2000) was added to the Atm-deficient cultures, survival was enhanced from 40 to $60 \%$ after $10 \mathrm{~d}$ in culture (data not shown).

\section{Nitroxide antioxidant protects Atm-deficient Purkinje cells against cell death}

Nitroxides are stable free radicals that protect against oxidative and radiation-induced cytotoxicity (Hahn et al., 1994). These molecules scavenge other free radicals and act as superoxide dismutase mimics (Damiani et al., 2000). We have recently addressed the solubility limitations of currently available isoindoline nitroxides by synthesizing CTMIO (Bottle et al., 2000), a compound that preserves the advantages of the isoindoline systems while possessing water solubility up to $2 \mathrm{~mm}$ (Fig. 1). Because oxidative stress might contribute to enhanced cell death of Atm gene-disrupted Purkinje neurons, we determined whether CTMIO would protect these cells against cell death. For Atm$\Delta$ SRI litters, CTMIO $(100 \mu \mathrm{M})$ did not appreciably affect the survival of Purkinje cells from the wild-type animals nor did it significantly change the $4 \mathrm{~d}$ survival of cells from Atm- ${ }^{\Delta \text { SRI/ }} \Delta$ SRI homozygote mice (Table 2 ). It had a very significant effect, however, on $10 \mathrm{~d}$ cultures in which nitroxide-treated cells had survival values $77 \%$ of wild-type ( $p=0.25$ ) compared with $32 \%$ survival for untreated Atm- $\Delta$ SRI cultures $(p<0.03)$ (Table 2). A similar pattern was obtained with Atm knock-out litters. A small effect in wild-type cell survival was observed but no enhanced survival for the $\mathrm{Atm}^{-1-} 4 \mathrm{~d}$ cultures. After $10 \mathrm{~d}$, however, treated cells had $59 \%$ of wild-type survival, double that recorded in untreated Atm cultures (31\%) (Table 2). The difference between $\mathrm{Atm}^{-1-}$ untreated and those treated with nitroxide was not significant $(p<$ 0.09 ) but can be explained by the smaller number of animals used in these experiments. These results suggest that disruption of the

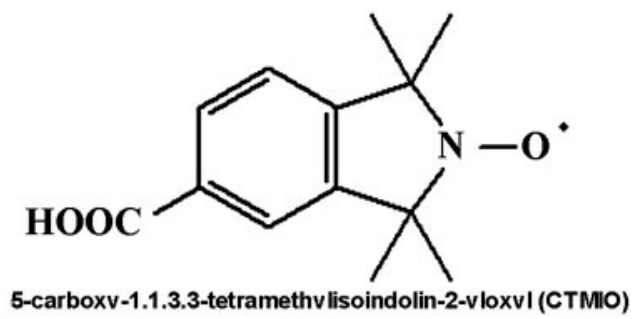

Figure 1. Structure of the isoindoline nitroxide, CTMI0. This compound was synthesized as described by Bottle et al. (2000) and is water soluble up to $2 \mathrm{~mm}$.

\section{Table 2. Effect of nitroxide on Atm-deficient Purkinje cell survival}

\begin{tabular}{|c|c|c|c|}
\hline Litter & Animal numbers & $4 \mathrm{DIV}^{a}$ & 10 DIV \\
\hline \multicolumn{4}{|l|}{ Atm- $\Delta$ SRI colony } \\
\hline $\mathrm{Atm}^{+/+b}$ & 5 & $201^{c} \pm 37^{d}$ & $165 \pm 30$ \\
\hline $\mathrm{Atm}^{+/+}+$nitroxide & 5 & $211 \pm 50$ & $155 \pm 26$ \\
\hline $\operatorname{Atm}^{\Delta S R I / \Delta S R I}$ & 5 & $105 \pm 29$ & $53 \pm 10$ \\
\hline$A_{t m}^{\Delta S R I / \Delta S R I}+$ nitroxide & 5 & $118 \pm 17$ & $119 \pm 23$ \\
\hline \multicolumn{4}{|l|}{ Atm $^{-1-}$-deficient colony } \\
\hline $\mathrm{Atm}^{+/+}$ & 3 & $182 \pm 35$ & $144 \pm 31$ \\
\hline $\mathrm{Atm}^{+/+}+$nitroxide & 3 & $233 \pm 49$ & $153 \pm 16$ \\
\hline $\mathrm{Atm}^{-1-}$ & 3 & $104 \pm 26$ & $45 \pm 13$ \\
\hline $\mathrm{Atm}^{-1-}+$ nitroxide & 3 & $111 \pm 26$ & $90 \pm 23$ \\
\hline
\end{tabular}

${ }^{a}$ DIV, Days in culture.

${ }^{b}$ Wild-type siblings from Atm- $\Delta$ SRI litters.

Numbers represent Purkinje neurons in $5 \mathrm{~mm}^{2}$ field.

${ }^{d}$ SEM.

Atm gene leads to oxidative stress, which contributes to the reduced survival of Purkinje neurons in vitro.

\section{Dendritic elongation and branching of Purkinje neurons}

Maintenance of rat cerebellar Purkinje neurons under dissociated culture conditions leads to phenotypic maturation, in particular dendritogenesis of these neurons (Furuya et al., 1998). Here we determined whether mouse cerebellar Purkinje cell cultures undergo this phenotypic maturation and whether the defect in survival of Atm gene-disrupted cultures would be reflected in a deficiency in dendritogenesis. Purkinje cells were detected by calbindin staining and categorized on the number of primary dendrites, ranging from one to five. The results in Table 3 outline the numbers and percentages of neurons in the different categories for Atm- $\Delta$ SRI and Atm knock-out litters. For Atm- $\Delta$ SRI litters, neurons from wild-type animals had differentiated to give cells with primarily complex arborization patterns (three to five primary dendrites). Sixty-eight percent of these neurons were in this category, with $32 \%$ being in the more simple, less differentiated form (one to two dendrites) (Table 3). Examples of these are shown in Figure $2 \mathrm{~A}$. When nitroxide was added to these cultures, the pattern of arborization was much the same, with $69 \%$ of cells having three to five primary dendrites. On the other hand, Purkinje neurons from Atm- ${ }^{\Delta \mathrm{SRI} / \Delta \mathrm{SRI}}$ homozygotes were poorly differentiated under these conditions, showing essentially a reversal of the pattern observed in wild-type cultures. Most of the cells had one to two primary dendrites ( $73 \%$ ), whereas only $27 \%$ of cells had more than three dendrites (Table 3). As is evident from Figure $2 B$, these neurons are quite deficient in extent of arborization. As a further measure of complexity, we determined the number of secondary branches for both categories. For the simple branch category, there was an average of $4.3 \pm 1.2$ secondary branches in the wild-type culture and $3.3 \pm 1.1$ in the Atm- $\Delta$ SRI cultures $(p<0.002)$. When complex-form dendrites were examined, the average number of secondary branches for wild-type cultures was $7.0 \pm 1.3$ compared with $5.9 \pm 1.0$ for Atm- $\Delta$ SRI $(p<0.004)$. As was observed for survival of Atm- $\Delta$ SRI Purkinje cells, CTMIO antioxidant had a dramatic effect on dendritic elongation and branching (Fig. 3). The pattern of dendritogenesis was much like that in wild-type neurons: $71 \%$ of cells showed a complex pattern, whereas $29 \%$ had one to two dendrites per cell body (Table 3 ).

In Atm knock-out litters, Purkinje neurons from wild-type mice showed evidence of differentiation to the same extent as in their counterparts from the Atm- $\Delta$ SRI litters (Table 3). Atm ${ }^{-1-}$ homozygotes, however, were deficient in dendritogenesis, exhib- 
Table 3. Dendritogenesis in Atm gene-disrupted mice

\begin{tabular}{|c|c|c|c|c|c|c|c|c|}
\hline \multirow[b]{2}{*}{ Litter } & \multirow[b]{2}{*}{ Neuron numbers } & \multicolumn{5}{|c|}{ No of primary dendrites } & \multirow{2}{*}{$\begin{array}{l}\text { Simple form } \\
\text { (one to two } \\
\text { dendrites) }{ }^{a}(\%)\end{array}$} & \multirow{2}{*}{$\begin{array}{l}\text { Complex form } \\
\text { (three to five } \\
\text { dendrites) }{ }^{b}(\%)\end{array}$} \\
\hline & & 1 & 2 & 3 & 4 & 5 & & \\
\hline \multicolumn{9}{|l|}{ Atm- $\Delta$ SRI colony } \\
\hline $\mathrm{Atm}^{+/+\mathrm{c}}$ & 178 & $6(3.3 \%)$ & $52(29.2 \%)$ & $89(50 \%)$ & $23(12.9 \%)$ & $8(4.5 \%)$ & 32 & 68 \\
\hline $\mathrm{Atm}^{+/+}+$nitroxide & 76 & $3(3.9 \%)$ & $21(27.6 \%)$ & $42(55 \%)$ & $10(13.1 \%)$ & $0(0 \%)$ & 31 & 69 \\
\hline $\mathrm{Atm}^{\Delta S R I / \Delta S R I}$ & 149 & $30(20 \%)$ & $79(53 \%)$ & $29(19.4 \%)$ & $7(4.7 \%)$ & $3(2 \%)$ & 73 & 27 \\
\hline$A t m^{\Delta S R I / \Delta S R I}+$ nitroxide & 246 & $12(4.8 \%)$ & $58(23.6 \%)$ & $111(45.1 \%)$ & $60(24.3 \%)$ & $5(2 \%)$ & 29 & 71 \\
\hline \multicolumn{9}{|l|}{ Atm $^{-1-}$-deficient colony } \\
\hline $\mathrm{Atm}^{+/+}$ & 248 & $5(2 \%)$ & $40(16.2 \%)$ & $110(44.7 \%)$ & $77(31.3 \%)$ & $16(6.5 \%)$ & 18 & 82 \\
\hline $\mathrm{Atm}^{+/+}+$nitroxide & 90 & $3(3.3 \%)$ & $17(18.8 \%)$ & $50(55 \%)$ & $17(18.9 \%)$ & $3(3 \%)$ & 23 & 77 \\
\hline $\mathrm{Atm}^{-1-}$ & 262 & $45(17.0 \%)$ & $141(53.4 \%)$ & $66(2.5 \%)$ & $10(3.8 \%)$ & $0(0)$ & 71 & 29 \\
\hline $\mathrm{Atm}^{-1-}+$ nitroxide & 127 & $0(0 \%)$ & $29(22.8 \%)$ & $67(52.7 \%)$ & $28(22 \%)$ & $3(2.3 \%)$ & 23 & 77 \\
\hline
\end{tabular}

${ }^{a}$ There are an average of 4.3 secondary branches in $+/+$ and 3.3 in $-1-$ Purkinje cells for simple form dentrites.

${ }^{b}$ The complex form has an average of seven branches for $+/+$ and 5.9 for $-/-$ Purkinje cells.

Wild-type in Atm- $\Delta$ SRI litters.

iting $71 \%$ simple-form dendrites, and only $29 \%$ of cells had three to five primary dendrites. The effect of the antioxidant was also dramatic in this case, reversing the pattern of dendritogenesis to $77 \%$ complex form and $23 \%$ simple form. Here again the evidence points to oxidative stress as a contributor to the deficient dendritogenesis.

\section{Effect of administration of antioxidant in vivo}

To determine whether the oxidative stress arose as a consequence of culturing Atm-deficient neurons or whether it was inherent in these animals, we pretreated pregnant females with nitroxide. The compound $(100 \mu \mathrm{M})$ was administered intraperitoneally before mating and at intervals of $3 \mathrm{~d}$ thereafter, before birth of the litter. The results in Table 4 reveal that survival of Purkinje cells from Atm mutant mice from mothers treated with nitroxide was somewhat elevated $(143 \pm 15.5$ and $139 \pm 11.2)$ compared with results from untreated animals $(113 \pm 18.7)$ after $4 \mathrm{~d}$ in culture. When nitroxide was also added to the cultures, survival was enhanced at the $10 \mathrm{~d}$ point compared with those in which nitroxide was not maintained, regardless of whether the mother was pretreated.

We also assessed the effect of previous in vivo administration of nitroxide on the cerebellum of mice 2 months after birth. In this case also, mice were treated with nitroxide during pregnancy and up to weaning. Nitroxide was then added to the drinking water of the litter up to 2 months of age. Clearly it was not possible to prepare neuronal cultures at this stage. Accordingly, two indicators of oxidative stress in the cerebellum, catalase activity and 3-nitrotyrosine, both of which are abnormal in the cerebellum from Atm gene-disrupted mice, were used to assess protection by antioxidant. As reported previously in fibroblasts (Kamsler et al., 2001; Stern et al., 2002), catalase activity was significantly reduced in cerebellar extracts from $\mathrm{Atm}_{-}{ }^{\Delta \mathrm{SRI} / \Delta \mathrm{SRI}}$ homozygotes compared with wild-type littermates, and previous in vivo treatment with nitroxide enhanced the level of activity to wild-type levels (Table 5). This was also the case for Atm knockout mice. Previous results have shown that Atm-deficient mice have elevated nitrotyrosine in the brain, a measure of oxidative stress (Barlow et al., 1999). Our results demonstrate that Purkinje cells from cerebella of Atm- ${ }^{\Delta \mathrm{SRI} / \Delta \mathrm{SRI}}$ and Atm ${ }^{-1-}$ homozygote mice have elevated levels of nitrotyrosine compared with wildtype (Fig. 4). This staining was particularly evident in the Purkinje cell layer. Remarkably, when nitroxide was administered throughout the pregnancy and up to 2 months after birth, nitrotyrosine-positive Purkinje cells decreased significantly in Atm- ${ }^{\Delta \mathrm{SRI} / \Delta \mathrm{SRI}}$ and $\mathrm{Atm}^{-1-}$ animals (Fig. 4).

\section{Discussion}

The data presented here provide additional evidence that neurodegenerative changes are part of the phenotype in Atm genedisrupted mice and that oxidative stress contributes to this phenotype. Gross neurodegeneration, characteristic of the human disease A-T (Boder, 1985), has not been observed in Atmdeficient mice (Barlow et al., 1996; Xu et al., 1996). It has been suggested that the early demise of $\mathrm{Atm}^{-1-}$ animals from thymic lymphomas may conceal the development of neurodegenerative

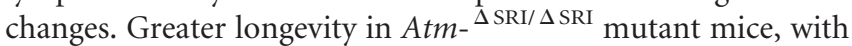
no evidence of neurodegeneration, failed to support this contention (Spring et al., 2001); however, closer inspection has revealed abnormalities in the cerebellum of Atm mutant mice. Electron microscopy has detected both subtle and gross neuronal abnormalities enriched in $\mathrm{Atm}^{-1-}$ mice (Kuljis et al., 1997); however, Barlow et al. (2000), using the same mice, did not observe any significant differences between wild type and $\mathrm{Atm}^{-1-}$ when regions throughout the cerebellar cortex and the fastigial nucleus were evaluated by electron microscopy. No degenerating Purkinje cells were evident. Immunostaining of Purkinje cells from 4- to 12 -month-old $A_{t m}^{y / y}$ ( $\operatorname{Rad} 3$ homology domain replaced with neo ${ }^{r}$ gene) revealed irregular patterns of cell dendrites (Borgeshani et al., 2000). Visualization of dendritic trees with Lucifer yellow dye demonstrated premature branching from the cell body and projection at odd angles in the molecular layer. Changes in dendritic arborization correlated with reduced thickness of the molecular layer. Increased numbers of ectopically located Purkinje cells were observed in this layer, but Purkinje cells were present at normal density in these mice. Although most of the studies do not support gross morphological change in the cerebellum of Atm-deficient mice, there is good evidence for abnormalities at the molecular level (Barlow et at 1999; Watters et al., 1999; Kamsler et al., 2001; Stern et al., 2002). It is not immediately obvious why such a difference exists between the mouse models and the human syndrome, but it could be attributable to species difference. The requirement for ATM in the developing brain of humans may be more critical, or redundancy mechanisms may exit in mouse neurons. We have exposed a defect in Purkinje cells in vitro by showing that Atm-deficient cells survive poorly and are markedly deficient in phenotypic maturation, as evidenced by abnormal dendritogenesis. Because these cells are not exposed to DNA damaging agents, it suggests that Atm functions at other levels in neurons. This is consistent with the predominantly cytoplasmic localization of Atm in Purkinje cells (Barlow et al., 2000). In addition, Oka and Takashima (1998) 
A
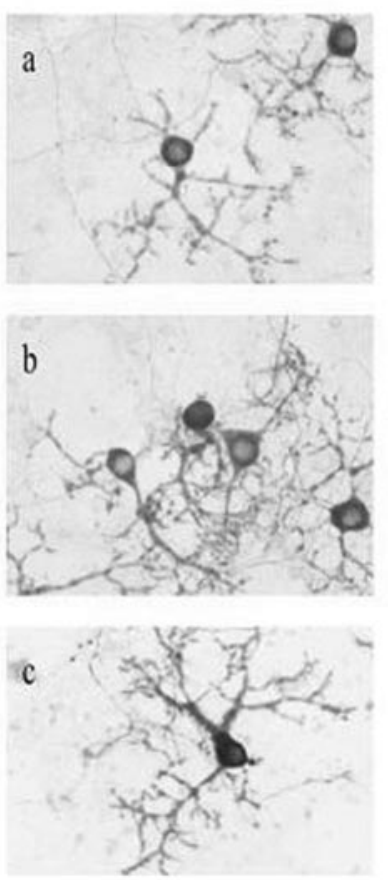

B
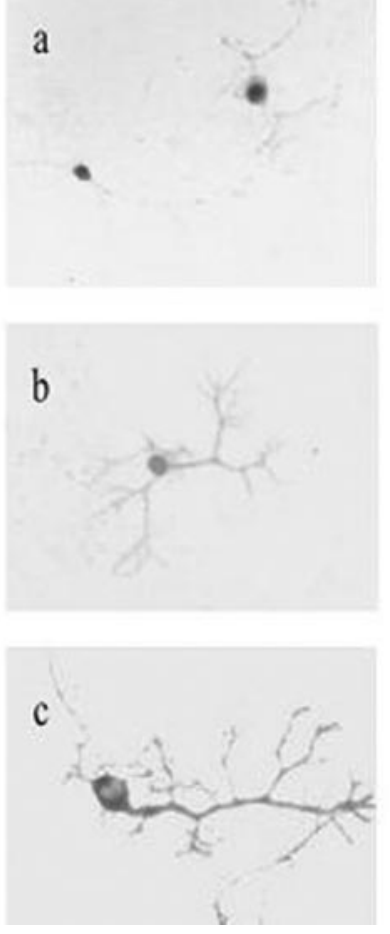
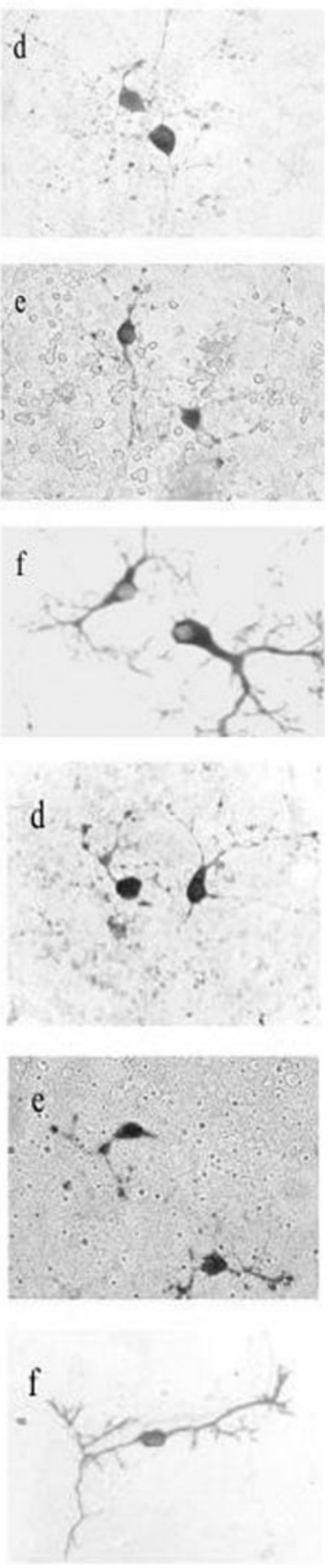

Figure 2. Survival and differentiation of Purkinje cells in culture. $A$, Calbindin-stained Purkinje cells from wild-type and Atm- $\Delta$ SRI homozygous mice. a-c are typical examples of dentritogenesis in wild-type $(+/+)$ Purkinje neurons, and $d-f$ are corresponding neurons from Atm- $\Delta \mathrm{SRI}$ cultures (Atm ${ }^{\Delta \mathrm{SRI} / \Delta \mathrm{SRl}}$ ). B, Calbindin-stained Purkinje neurons from $\mathrm{Atm}^{-1-}$ mice. $a-f$ are typical examples of Purkinje cells from Atm ${ }^{-1-}$-deficient mice. Note the poor degree of differentiation compared with wild-type cells. All Purkinje neurons were isolated from cerebella of day 0 mice and maintained in culture for $10 \mathrm{~d}$ as described in Materials and Methods.

have provided evidence for cytoplasmic localization of Atm in human Purkinje cells but did not include negative controls in their study. ATM has also been detected in the cytoplasm of proliferating cells but with much less abundance than in the nu-
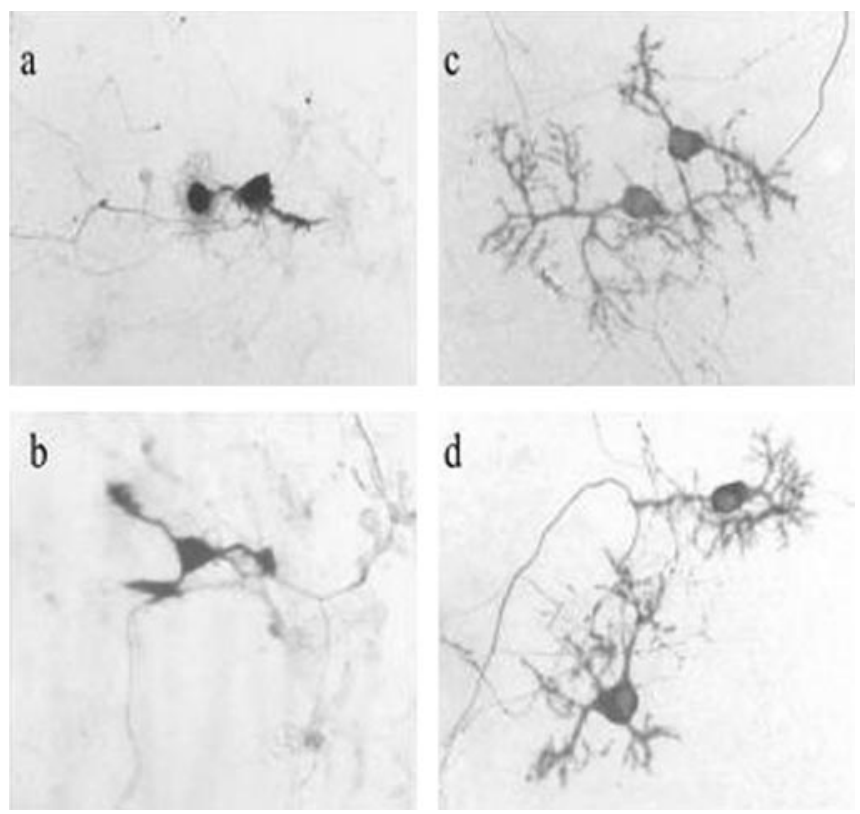

Figure 3. Effect of the nitroxide CTMI0 on dentritogenesis in Purkinje neurons isolated from the cerebella of Atm- $\Delta$ SRI homozygous mice (Atm ${ }^{\Delta S R I / \Delta S R l}$ ). Neurons from Atm ${ }^{\Delta S R I / \Delta S R I}$ mice were plated out at day 0 in the absence $(a, b)$ or presence $(c, d)$ of CTMI0 $(100 \mu \mathrm{M})$. Additional CTMIO $(100 \mu \mathrm{m})$ was added to the cultures at $3 \mathrm{~d}$ intervals for the $10 \mathrm{~d}$ period of culture. Samples were fixed and calbindin staining was performed to detect surviving Purkinje cells. The neurons depicted are representative of the extent of dentritogenesis observed in treated $(c, d)$ and untreated $(a, b)$ cultures.

Table 4. Effect of previous treatment of pregnant females with nitroxide

\begin{tabular}{|c|c|c|}
\hline Nitroxide treatment & 4 DIV ( \pm SEM) & 10 DIV ( \pm SEM) \\
\hline Throughout pregnancy only (6) ${ }^{a}$ & $143 \pm 15.5$ & $64 \pm 4.1$ \\
\hline During pregnancy and in cultures (6) & $139 \pm 11.2$ & $125 \pm 8.3$ \\
\hline Untreated (20) & $113 \pm 18.7$ & $59 \pm 2.5$ \\
\hline
\end{tabular}

${ }^{a}$ Numbers in parentheses represent the number of animals.

Table 5. Catalase activity in cerebellum from wild-type and Atm gene disrupted mice

\begin{tabular}{ll}
\hline Litter & Catalase activity units per milligram protein \\
\hline Atm- $\Delta$ SRI colony & \\
$\mathrm{Atm}^{+/+a}$ & $37.4 \pm 8.9^{b}$ \\
$\mathrm{Atm}^{+/+b}+$ nitroxide & $37.5 \pm 6.3$ \\
$\mathrm{Atm}^{\Delta S R I / \Delta S R I}$ & $20.3 \pm 4.6$ \\
$\mathrm{Atm}^{\Delta S R / \Delta S R I}+$ nitroxide & $37.1 \pm 6.5$ \\
$\mathrm{Atm}^{-/-}$-deficient colony & \\
$\mathrm{Atm}^{+/+}$ & $37.4 \pm 5.9$ \\
$\mathrm{Atm}^{+/+}+$nitroxide & $40.8 \pm 7.3$ \\
$\mathrm{Atm}^{-/-}$ & $28.3 \pm 7.3$ \\
$\mathrm{Atm}^{-/-}+$nitroxide & $40.1 \pm 5.6$ \\
\hline
\end{tabular}

${ }^{a}$ Refers to wild-type in Atm- $\Delta$ SRl litters.

${ }^{b}$ Results are from an average of five animals per group. \pm refers to SEM.

cleus (Watters et al., 1999). Although activation of cytoplasmic ATM kinase has not been demonstrated, this enzyme is activated by insulin to phosphorylate e1F-4E-binding protein 1, which stimulates protein synthesis (Yang and Kastan, 2000). ATM is also activated in response to nutrient deprivation downstream of Akt and a novel AMP-activated protein kinase, ARK5 (Suzuki et al., 2003). Thus, ATM can respond to stimuli other than the appearance of DNA double strand breaks.

Almost complete absence of radiation-induced apoptosis is observed in the hippocampal dentate gyrus, retina, cerebellum, 


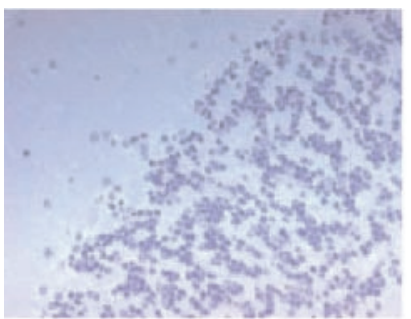

$\mathrm{Atm}^{+/+}$

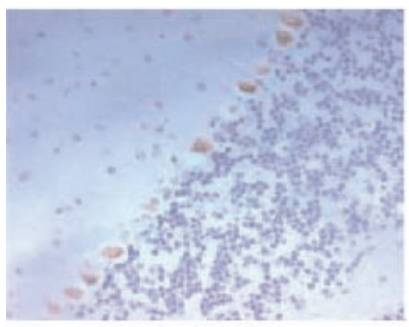

$\mathrm{Atm}^{\Delta \mathrm{SRI} / \Delta \mathrm{SRI}}$

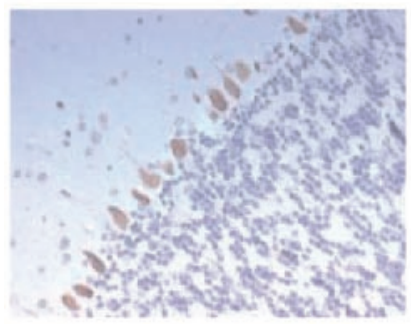

$\mathrm{Atm}^{-/-}$

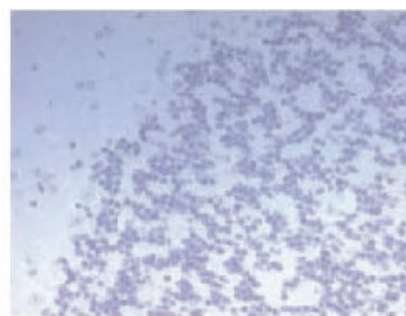

$\mathrm{Atm}^{+/+}+$Nitroxide

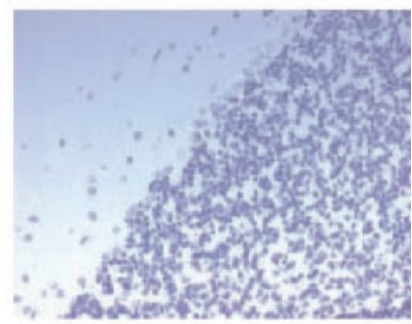

Atm ${ }^{\Delta \text { SRI } / \Delta \text { SRI }}+$ Nitroxide

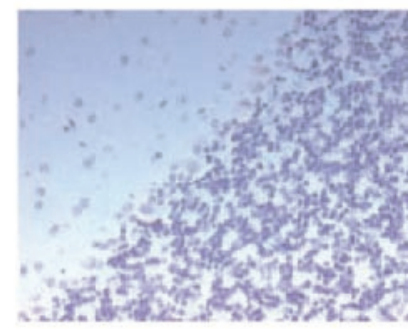

$\mathrm{Atm}^{-/-}+$Nitroxide
Figure 4. Immunostaining of Purkinje cells from wild-type, $A_{t m}{ }^{-1-}$, and Atm- ${ }^{\Delta S R I / \Delta S R I}$ homozygous mice cerebella sections for 3-nitrotyrosine. Cerebella were isolated from 2-monthold mice treated or untreated with CTMI0 antioxidant and fixed in paraformaldehyde; $5 \mu \mathrm{M}$ sections were prepared and incubated with anti-nitrotyrosine antibody and HRP-linked secondary antibody. CTMIO was administered intraperitoneally to pregnant female mice at $3 \mathrm{~d}$ intervals throughout pregnancy and during weaning. Thereafter CTMIO (100 $\mu \mathrm{M})$ was added to the drinking water.

and cerebral cortex of Atm-deficient mice (Herzog et al., 1998); however, less well differentiated cells of the subventricular zone exhibited radiation-induced apoptosis, albeit to a reduced extent, in $\mathrm{Atm}^{-1-}$ mice. These results suggest that Atm functions at a developmental survival checkpoint to eliminate more mature neurons with excessive DNA damage. Our results point to an additional pro-survival role for Atm in maintaining the normal development of neurons. Expression patterns of Atm in human cerebellar neurons during development support this (Oka and Takashima, 1998). Cerebellar neurons, particularly Purkinje cells, were positive for Atm during late prenatal and early postnatal periods followed by persistent and moderate reactivity in Purkinje cells. In the mouse, Atm expression is highest in the embryonic nervous system (Soares et al., 1998). During Purkinje cell neurogenesis, Atm is highly expressed in the area containing Purkinje cell precursors, whereas in the postnatal cerebellum Atm expression in these cells is low. Recent data also demonstrate that Atm is essential for the normal development and differentiation of adult neural progenitor cells (Allen et al., 2001). Cells of the dentate gyrus of Atm-I- mice showed significantly decreased survival compared with wild-type mice. Furthermore, neural progenitor cells from $\mathrm{Atm}^{-1-}$ mice were less able to respond to environmental cues that promote neural differentiation. Our failure to observe any survival of Purkinje neurons from Atmdeficient mice when cultured in serum-free medium together with poor survival and differentiation in serum-supplemented medium further highlights the importance of Atm in the response to survival stimuli. A broader role for ATM is also evident in other cell types. A-T fibroblasts exhibit a greater demand for growth factors (Shiloh et al., 1982). A-T cells are deficient in the transmission of mitogen-mediated signals from the cytoplasm to the nucleus (O'Connor and Linthicum, 1980), and these cells are defective in the mobilization of intracellular $\mathrm{Ca}^{2+}$ in response to different stimuli (Kondo et al., 1983; Khanna et al., 1997).

Various oxidants are generated in the cell during normal metabolism, and there is evidence that some of these modulate different signaling pathways (Nemoto et al., 2000; Pearce and Humphrey, 2001). Yermolaieva et al. (2000) have described oxidative potentiation of neuronal excitability and $\mathrm{Ca}^{2+}$ signaling, linking neuronal development factors such as nitric oxide with neuronal differentiation; however, when there is an imbalance between generation of reactive oxygen species and capacity of antioxidants to neutralize their damaging effects, oxidative stress results (Przedborski and Schon, 1998). Oxidative stress has been linked to the pathogenesis of a number of neurodegenerative disorders (Hogg, 1998; Miranda et al., 2000). Agents such as nitroxides that counter oxidative stress have potential as protectors of neuronal function. Significant attenuation of staurosporine-induced neurotoxicity has been reported for EUK-134 and EUK-189, two synthetic superoxide dismutase-catalase mimetics (Pong et al., 2001). The former antioxidant has also been shown to be successful in protecting dopaminergic neurons against oxidative damage (Pong et al., 2000), and it also attenuates kainic acid-induced neuropathology (Rong et al., 1999). Early observations on abnormal oxidation of macromolecules in A-T patients together with hypersensitivity to agents that induce oxidative stress led Rotman and Shiloh (1997) to propose that oxidative stress might contribute to the A-T phenotype. The data described in this report, where the isoindoline nitroxide CTMIO protects cultured Purkinje cells against death and enhances differentiation, together with several recent reports, adds considerable substance to the involvement of oxidative stress in the A-T phenotype. Pathways that respond to genotoxic stress are elevated in A-T cells and can be reversed by antioxidants (Gatei et al., 2001). In addition, the cerebellum, which undergoes pathological changes in A-T patients and in Atm-deficient mice, is a target for oxidative damage (Barlow et al., 1999; Kamsler et al., 2001; Stern et al., 2002). Consistent with these findings, Quick and Dugan (2001) have described increased reactive oxygen species in the cerebellum and striatum of $\mathrm{Atm}^{-1-}$ mice compared with wild type. They detected elevated superoxide levels in cerebellar Purkinje cells. Constitutive activation of the activation protein-1 (AP-1) pathway and gradual loss of ability to activate AP-1 DNA binding activity after irradiation in brains from Atm-deficient mice also point to a continuous state of stress in these animals (Weizman et al., 2003). At this stage it is not clear why oxidative stress arises in A-T cells and tissues. The presence of unrepaired double strand breaks in DNA caused by the absence of Atm might lead to a perturbation of metabolism and alteration in redox state. Stern et al. (2002) have reported reductions in pyridine nucleotides, specifically in the cerebellum of Atm-deficient mice, that could lead to alterations in cellular homeostasis. Alternatively, ATM may be responsible for controlling oxidative stress pathways by gene induction or protein modification and activation, and its loss would give rise to deregulation of those pathways, resulting in oxidative stress. It has been reported that astrocytes provide var- 
ious trophic factors and anti-oxidative components to neurons (Furuya et al., 2000; Wang and Cynader, 2001). The observation that Purkinje call survival of Atm-deficient mice is partially reversed by the presence of nitroxide or astrocytic-conditioned medium suggests that loss of ATM function results in a reduced ability of astrocytes to protect surrounding Purkinje cells against oxidative stress. The effectiveness of nitroxide in providing protection in young mice is good evidence that the oxidative stress in A-T cells is not merely an in vitro phenomenon. The low toxicity of this compound and its ability to provide in vivo protection suggest that it has potential for use in clinical trials to at least reduce the rate of progression of the neurodegeneration in patients.

\section{References}

Allen DM, van Praag H, Ray J, Weaver Z, Winrow CJ, Carter TA, Braquet R, Harrington E, Ried T, Brown KD, Gage FH, Barlow C (2001) Ataxia telangiectasia mutated is essential during adult neurogenesis. Genes Dev 15:554-566.

Barlow C, Hirotsune S, Paylor R, Liyanage M, Eckhaus M, Collins P, Shiloh Y, Crawley JN, Ried T, Tagle D, Wynshaw-Boris A (1996) Atm-deficient mice: a paradigm of ataxia telangiectasia. Cell 86:159-171.

Barlow C, Dennery PA, Shigenaga MK, Smith MA, Morrow JD, Roberts LJ, Wynshaw-Boris A, Levine RL (1999) Loss of the ataxia-telangiectasia gene product causes oxidative damage in target organs. Proc Natl Acad Sci USA 96:9915-9919.

Barlow C, Ribaut-Barassin C, Zwingman TA, Pope AJ, Brown KD, Owens JW, Larson D, Harrington EA, Haeberle AM, Mariani J, Eckhaus M, Herrup $\mathrm{K}$, Bailly Y, Wynshaw-Boris A (2000) ATM is a cytoplasmic protein in mouse brain required to prevent lysosomal accumulation. Proc Natl Acad Sci USA 97:871-876.

Boder E (1985) Ataxia-telangiectasia: an overview. In: Ataxia-telangiectasia genetics, neuropathology, and immunology of a degenerative disease of childhood (Gatti R, Sibt M, eds), pp 1-63. New York: Alan R. Liss.

Borgeshani PR, Alt FW, Bottaro A, Davidson L, Aksoy S, Rathbun GA, Roberts TM, Swat W, Segal RA, Gu Y (2000) Abnormal development of Purkinje cells and lymphocytes in Atm mutant mice. Proc Natl Acad Sci USA 97:3336-3341.

Bottle SE, Gillies DG, Hughes DL, Micallef AS, Smirnov A, Sutcliffe LH (2000) Synthesis, single crystal X-ray structure and W-band $(95 \mathrm{GHz})$ EPR spectroscopy of a new anionic isoindoline aminoxyl: synthesis and characterization of some derivatives. J Chem Soc Perkins 227:1285-1291.

Crawford TO, Mandir AS, Lefton-Grief MA, Goodman SN, Goodman BK, Sengul H, Lederman HM (2000) Quantitative neurologic assessment of ataxia-telangiectasia. J Neurol 54:1505-1509.

Damiani E, Kalinska B, Canapa A, Canestrari S, Wozniak M, Olmo E, Greci L (2000) The effects of nitroxide radicals on oxidative DNA damage. Free Radic Biol Med 28:1257-1265.

Elson A, Wang Y, Daugherty CJ, Morton CC, Zhou F, Campos-Torres J, Leder P (1996) Pleiotropic defects in ataxia-telangiectasia proteindeficient mice. Proc Natl Acad Sci USA 93:13084-13089.

Furuya S, Makino A, Hirabayashi Y (1998) An improved method for culturing cerebellar Purkinje cells with differentiated dendrites under a mixed monolayer setting. Brain Res Protoc 3:192-198.

Furuya S, Tabata T, Mitoma J, Yamada K, Yamasaki M, Makino A, Tamamoto T, Watanabe M, Kano M, Hirabayashi Y (2000) L-serine and glycine serve as major astroglia-derived trophic factors for cerebellar Purkinje neurons. Proc Natl Acad Sci USA 97:11528-11533.

Gatei M, Shkedy D, Khanna KK, Uzie T, Shiloh Y, Pandita TK, Lavin MF, Rotman G (2001) Ataxia-telangiectasia: chronic activation of damageresponsive functions is reduced by alpha-lipoic acid. Oncogene 20:289-294.

Hahn SM, Krishna CM, Michell JB (1994) New directions for free radical cancer research and medical applications. Adv Exp Med Biol 336:241-251.

Herzog KH, Chong MJ, Kapsetaki M, Morgan JI, McKinnon PJ (1998) Requirement for Atm in ionizing radiation-induced cell death in the developing central nervous system. Science 280:1089-1091.

Hogg N (1998) Free radicals in disease. Semin Reprod Endocrinol $16: 241-248$
Kamsler A, Daily D, Hockman A, Stern N, Shiloh Y, Rotman G, Barzilai A (2001) Increased oxidative stress in ataxia telangiectasia evidenced by alterations in redox state of brains from Atm-deficient mice. Cancer Res 61:1849-1854.

Khanna KK, Yan J, Watters D, Hobson K, Beamish H, Spring K, Shiloh Y, Gatti RA, Lavin MF (1997) Cellular localisation of the ataxiatelangiectasia (ATM) gene product and discrimination between mutated and normal forms. J Biol Chem 272:9483-9495.

Kondo N, Inoue R, Nishimura S, Kasahara K, Kameyama Y, Miwa Y, Lorenzo $\mathrm{R}$, Orii T (1983) Defective calcium-dependent signal transduction in $\mathrm{T}$ lymphocytes of ataxia-telangiectasia. Scand J Immunol 38:45-48.

Kuljis RO, Xu Y, Aguila MC, Baltimore D (1997) Degeneration of neurons, synapses, and neuropil and glial activation in a murine Atm knockout model of ataxia-telangiectasia. Proc Natl Acad Sci USA 94:12688-12693.

Lavin MF, Shiloh Y (1997) The genetic defect in ataxia-telangiectasia. Annu Rev Immunol 15:177-202.

Miranda KM, Espey MG, Wink DA (2000) A discussion of the chemistry of oxidative and nitrosative stress in cytotoxicity. J Inorg Biochem 79:237-240.

Nemoto S, Takeda K, Yu ZX, Ferrans VJ, Finkel T (2000) Role for mitochondrial oxidants as regulators of cellular metabolism. Mol Cell Biol 20:7311-7318.

O'Connor RD, Linthicum DS (1980) Mitogen receptor redistribution defects and concomitant absence of blastogenesis in ataxia-telangiectasia $\mathrm{T}$ lymphocytes. Clin Immunol Immunopathol 15:66-75.

Oka A, Takashima S (1998) Expression of the ataxia-telangiectasia gene (ATM) product in human cerebellar neurons during development. Neurosci Lett 252:195-198.

Pearce AK, Humphrey TC (2001) Integrating stress-response and cell-cycle checkpoint pathways. Trends Cell Biol 11:426-433.

Pong K, Doctrow SR, Baudry M (2000) Prevention of 1-methyl-4phenylpyridinium- and 6-hydroxydopamine-induced nitration of tyrosine hydroxylase and neurotoxicity by EUK-134, a superoxide dismutase and catalase mimetic, in cultured dopaminergic neurons. Brain Res 881:182-189.

Pong K, Doctrow SR, Huffman K, Adinolfi CA, Baudry M (2001) Attenuation of staurosporine-induced apoptosis, oxidative stress, and mitochondrial dysfunction by synthetic superoxide dismutase and catalase mimetics, in cultured cortical neurons. Exp Neurol 171:84-97.

Przedborski S, Schon EA (1998) Loss of ROS-a radical response. Nat Genet 18:99-100

Quick KL, Dugan LL (2001) Superoxide stress identifies neurons at risk in a model of ataxia-telangiectasia. Ann Neurol 49:627-635.

Rong Y, Doctrow SR, Tocco G, Baudry B (1999) EUK-134, a synthetic superoxide dismutase and catalase mimetic, prevents oxidative stress and attenuates kainate-induced neuropathology. Neurobiology 96:9897-9902.

Rotman G, Shiloh Y (1997) Ataxia-telangiectasia: is ATM a sensor of oxidative damage and stress? BioEssays 19:911-917.

Savitsky K, Bar-Shira A, Gilad S, Rotman G, Ziv Y, Vanagaite L, Tagle DA, Smith S, Uziel T, Sfez S, Ashkenazi M, Pecker L, Frydman M, Harnik R, Patanjali SR, Simmons A, Clines GA, Sartier A, Gatti RA, Chessa L, et al. (1995) A single ataxia telangiectasia gene with a product similar to PI-3 kinase. Science 268:1749-1753.

Sedgwick RP, Boder E (1991) Ataxia-telangiectasia (208900, 208910, 208920). In: Hereditary neuropathies and spinocerebellar atrophies (Vinkin PJ, Bruyn W, Klawans HL, eds), pp 347-423. New York: Alan R. Liss.

Shiloh Y, Kastan MB (2001) ATM: genome stability, neuronal development, and cancer cross paths. Adv Cancer Res 83:209-254.

Shiloh Y, Tabor E, Becker Y (1982) Colony-forming ability of ataxiatelangiectasia skin fibroblasts is an indicator of their early senescence and increased demand for growth factors. Exp Cell Res 140:91-99.

Soares HD, Morgan JI, McKinnon PJ (1998) Atm expression patterns suggest a contribution from the peripheral nervous system to the phenotype of ataxia-telangiectasia. Neuroscience 86:1045-1054.

Spring K, Cross S, Li C, Watters D, Ben-Senior L, Waring P, Ahangari F, Lu SL, Chen P, Misko I, Paterson C, Kay G, Smorodinsky NI, Shiloh Y, Lavin MF (2001) Atm knock-in mice harboring an in-frame deletion corresponding to the human ATM 7636del9 common mutation exhibit a variant phenotype. Cancer Res 61:4561-4568.

Spring K, Ahangari F, Scott SP, Waring P, Purdie DM, Chen PC, Hourigan K, Ramsay J, McKinnon PJ, Swift M, Lavin MF (2002) Mice heterozygous 
for mutation in Atm, the gene involved in ataxia-telangiectasia, have heightened susceptibility to cancer. Nat Genet 32:185-190.

Stern N, Hochman A, Zemach N, Weizman N, Hammel I, Shiloh Y, Rotman G, Barzilai A (2002) Accumulation of DNA damage and reduced levels of nicotine adenine dinucleotide in the brains of Atm-deficient mice. J Biol Chem 277:602-608.

Suzuki A, Kasakai G, Kishimoto A, Lu J, Ogura T, Lavin MF, Esumi H (2003) Identifcation of a novel protein kinase mediating Akt survival signaling to the ATM protein. J Biol Chem 278:48-53.

Wang XF, Cynader MS (2001) Pyruvate released by astrocytes protects neurons from copper-catalyzed cysteine neurotoxicity. J Neurosci 21:3322-3331.

Watters D, Kedar P, Spring K, Bjorkman J, Chen P, Gatei M, Birrell G, Garrone B, Srinivasa P, Crane DI, Lavin MF (1999) Localization of a portion of extranuclear ATM to peroxisomes. J Biol Chem 274:34277-34282.
Weizman N, Shiloh Y, Barzilai A (2003) Contribution of the Atm protein to maintaining cellular homeostasis evidenced by continuous activation of the AP-1 pathway in Atm-deficient brains. J Biol Chem 278:6741-6747.

Xu Y, Ashley T, Brainerd EE, Bronson RT, Meyn MS, Baltimore D (1996) Targeted disruption of ATM leads to growth retardation, chromosomal fragmentation during meiosis, immune defects, and thymic lymphoma. Genes Dev 10:2411-2422.

Yang DQ, Kastan MB (2000) Participation of ATM in insulin signalling through phosphorylation of eIF-4E-binding protein 1. Nat Cell Biol 2:893-898.

Yermolaieva O, Brot N, Weissbach H, Heinemann SH, Hoshi T (2000) Reactive oxygen species and nitric oxide mediate plasticity of neuronal calcium signaling. Proc Natl Acad Sci USA 97:448-453. 